\title{
Development of detached root and leaf assays to evaluate the antagonistic properties of biocontrol agents against Fusarium wilt of banana
}

\begin{abstract}
The failure of bio-control agents (BCAs) in suppressing Fusarium oxysporum f. sp. cubense tropical race 4 (Foc-TR4) was reported in vivo although antagonism was obtained from in vitro dual culture assay. This study aims to develop rapid assays to validate the antagonism of BCAs using detached banana leaves and roots. Both Trichoderma harzianum and Pseudomonas aeruginosa reduced root lesion length $(2.7-3.1 \mathrm{~cm})$ compared to $4.9 \mathrm{~cm}$ in TR4 treatment. BCAtreated leaves reduced wilting severity from 93.75 to $33.75 \%$. Trypan blue staining showed lower cell death area in BCA-treated roots and leaves. Reduced leaf wilting was indicated by lower red ink content and higher chlorophyll content in BCA-treated leaves. Both defenserelated genes, PR-1 and PR-3 were expressed in BCA-treated roots and leaves which could be associated with reduced root necrosis and leave wilting. In conclusion, both assays could be served as rapid methods to select potential BCAs before attempting large-scale trials.
\end{abstract}

Keyword: Banana; Biocontrol; Defense-related genes; Fusarium wilt; In vitro assays 